\title{
Exploração-dominação masculina no contexto capitalista
}

\author{
The male domination-exploitation in the capitalist context
}

Maria Cecilia Olivio*

\begin{abstract}
Resumo:
O presente texto tem por objetivo apresentar uma discussão teórica sobre alguns aspectos da simbiose entre capitalismo e patriarcado, a partir da compreensão da manutenção/vigência da dominação-exploração masculina. Apresenta breve dicussão sobre a categoria trabalho e a constituição do ser social. Contextualiza a discussão sobre as Relações Sociais de Sexo e o Patriarcado e considera que as relações sociais de sexo têm sua base material dada pela organização social capitalista, que atribui posições desiguais e hierarquizadas para mulheres e homens, ou seja, que essa conformação mantém a exploração-dominação masculina.
\end{abstract}

Palavras-chave: Exploração-dominação masculina; Relações sociais de sexo; Capitalismo; Patriarcado; Totalidade social.

\begin{abstract}
:
This paper aims to present a theoretical discussion about some aspects of the symbiosis of capitalism and patriarchy, from the understanding of maintenance/effectiveness of male domination-exploitation. Presents brief discussing about the category work and the constitution of the to be social. Contextualizes the discussion of Social Relations of Sex and the Patriarchy and considers that the social relations of sex have their material base given by the capitalist social organization that assign unequal and hierarchical positions for women and men, and that conformation maintains the male domination-exploitation
\end{abstract}

Key words: Male domination-exploitation; Social relations of sex; Capitalism; Patriarchy; Social totality.

\section{Introdução}

O presente texto tem por objetivo apresentar uma discussão teórica sobre alguns aspectos da simbiose entre capitalismo e patriarcado, a partir da compreensão da manutenção/vigência da dominação-exploração masculina. Partimos da necessidade de compreender algumas dimensões e ações que constituem a reprodução e a produção das relações sociais tendo como base a desigualdade inerente ao sistema capitalista e a desigualdade entre os sexos. Assim, entendemos que o desvelamento e a compreensão

\footnotetext{
*Assistente Social. Mestre em Serviço Social (UFSC). E-mail: mariaceciliaolivio@gmail.com
} 
dessas dimensões podem contribuir com as lutas que visam à construção de resistências e à superação de tais relações.

O objeto deste estudo é a relação que se estabelece entre o modo de produção capitalista e o patriarcado, focando especificamente alguns aspectos que determinam a compreensão da manutenção/vigência da dominação-exploração masculina ${ }^{1}$ na contemporaneidade. Nessa direção, é um estudo teórico que procura compreender algumas categorias que compõem o real e que também auxiliam na análise dos processos de transformação da relação entre o capitalismo e o patriarcado. Obviamente não temos a pretensão de esgostar as discussões desse tema, mas interessa fundamentalmente abordar como a categoria sexo - natural e inerente ao ser social - é tomada e capturada como marca de desigualdade entre os sujeitos e como essa "marca natural" se naturaliza e se metamorfoseia na complexificação das relações sociais, tendo seu ápice no modo de produção capitalista.

Assim a discussão ora apresentada, à luz da ontologia marxista, demandou intensa análise teórica, a guisa de oferecer a necessária fundamentação para o desenvolvimento da pesquisa. Compreendemos que a teoria é uma expressão da práxis e constitui uma ferramenta importante e fundamental para a compreensão da realidade, isto é, como bem expressa Marx, a teoria é uma modalidade peculiar de conhecimento,

[...]. Mas a teoria [...] tem especificidades: o conhecimento teórico é o conhecimento do objeto - de sua estrutura e dinâmica - tal como ele é em si mesmo, na sua existência real e efetiva, independentemente dos desejos, das aspirações e das representações do pesquisador. [Ela é] [...] a reprodução ideal do movimento real do objeto pelo sujeito que pesquisa: pela teoria, o sujeito reproduz em seu pensamento a estrutura e a dinâmica do objeto de pesquisa (NETTO, 2011, p. 20-21).

Portanto, a teoria é o real interpretado e reproduzido do plano do ideal. Assim, "o objeto da pesquisa tem existência objetiva" e o objetivo da pesquisa é apreender a estrutura e a dinâmica desse objeto, ou seja, "o método de pesquisa que propicia o conhecimento teórico, partindo da aparência, visa alcançar a essência do objeto" (NETTO, 2011, p. 21-22).

\footnotetext{
${ }^{1}$ Nas palavras de Saffioti (1990, p. 50): “Enquanto a dominação pode, para efeitos de análise, ser situada essencialmente nos campos político e ideológico, a exploração diz respeito diretamente ao terreno econômico".
} 
Nesse sentido, na presente pesquisa, procuramos ir para além da aparência naturalizada da manutenção e da vigência do processo de exploração-dominação masculina, buscando compreender como ela se sustenta nos marcos do capitalismo.

Por esse caminho, tornou-se importante perguntar: como essa característica inerente ao ser social, esse ser mulher e esse ser homem na sua diferença orgânica biológica, no processo da complexificação das relações - vai adquirindo formas e posições naquilo que por natureza os diferencia - o sexo - e se torna um elemento de dominação exploração masculina? Assim, e a partir da ontologia marxista, procuramos esclarecer e compreender o movimento e a complexificação das relações - as quais, em diferentes momentos históricos, produzem as desigualdades entre os sujeitos a partir de atributos naturais -, que na continuidade da reprodução social ao mesmo tempo sustentam e camuflam as contradições necessárias à ordem do capital.

Destarte, acreditamos ser necessária a qualquer luta que assuma o horizonte de contestação à ordem do capital e que reivindique a construção de uma nova sociabilidade, livre da exploração capitalista, colocar na ordem o dia o questionamento da conformação das relações sociais entre os sujeitos 2 na e pela ordem do capital - que são atravessadas por relações de exploração-dominação. Assim, partimos do pressuposto de que a luta pela emancipação humana3 - diante de todas as barreiras e ocultamentos impostos pela ordem do capital e dos meios privados de produção - requer vinculação orgânica com a destruição de todas as formas de dominação-exploração entre os sujeitos.

Em outras palavras, a dinâmica social capitalista é em si limitadora das potencialidades humanas e, portanto, da liberdade. E lança mão de diferentes estratégias

\footnotetext{
2 “[...] o sujeito se constitui socialmente, ou seja, é forjado nas e através das relações sociais. Não apenas o sujeito coletivo, mas também o sujeito individual não é senão a história de suas relações sociais. [...]. A construção do sujeito apresenta um caráter relacional. Isto significa que a formação do eu não pode prescindir de, no mínimo, outro eu ou, para ser mais fiel aos fatos, de outros eus. Desta sorte, sujeito e objeto não são senão uma diferenciação no interior da relação social, de acordo com a posição ocupada nos polos desta. Não há, pois, distinção substantiva entre um e outro, mas apenas uma diferença adjetiva. Também, por outra razão a diferença não participa da essência do sujeito/objeto: ela é historicamente situada, vale dizer, socialmente construída. A história não é o leito de Procusto representado pelo lema $a$ anatomia é o destino, o que elimina, ou pelo menos reduz drasticamente, o risco de absolutização do conceito de diferença" (SAFFIOTI, 1995, p. 159).

3 Sobre esse tema existem diferentes compreensões no campo do marxismo. Por exemplo, C.F.: Barroco (2003). Na área da Educação: Tonet (2012), entre outros estudiosos do tema.
} 
para estabelecer e reforçar a desigualdade necessária para a manutenção do seu modelo de relações sociais, entre elas, as relações sociais de sexo.

Mas, afinal, o que significa liberdade? Recorrendo a Agnes Heller, buscaremos situar brevemente tal questionamento.

\begin{abstract}
A liberdade é sempre liberdade para algo, e não apenas liberdade de algo. Se interpretamos a liberdade apenas como o fato de sermos livres de alguma coisa, encontramo-nos no estado de arbítrio, definimo-nos de modo negativo [...]. 0 próprio conceito de liberdade contém o conceito de regra, de reconhecimento, de intervenção recíproca. Com efeito, ninguém pode ser livre se, em volta dele, há outros que não o são (HELLER, 1982, p. 155).
\end{abstract}

Liberdade de algo é uma liberdade parcial, significa estar livre de algo. Liberdade para algo, uma liberdade total, expressa a possibilidade de agir no sentido desejado. Esta, por sua vez, mediante a autodeterminação dos diferentes sujeitos, livremente associados a outros sujeitos, permite o desenvolvimento pleno de suas potencialidades, na direção do humano genérico.

A liberdade parcial é precondição para a liberdade total. No que se refere às desigualdades de sexo, a liberdade parcial é um "momento da luta, mas só possui um verdadeiro sentido se acompanhado por um vínculo indissolúvel com a emancipação humana" (VIANA, 2010, p. 41).

Nessa perspectiva, a luta pela construção de uma nova sociabilidade passa, invariavelmente, pela luta contra todas as determinações desiguais que conformam os sujeitos e que estes, ainda, reproduzem. Para tanto, todas as relações devem ser repensadas e reconstruídas com tenacidade e firmeza a cada dia, a cada passo, a cada erro. O questionamento do hegemonicamente posto nas relações amorosas, conjugais, familiares, afetivas, interpessoais, relações assimétricas no trabalho, fazem parte da construção de uma sociedade sem oprimidos e sem opressores. Sem oprimidas e sem opressoras.

Consideramos que a conformação das relações sociais na ordem do capital é atravessada pela contradição fundamental de classe, que tem sua complexificação expressa pelas relações desiguais estabelecidas também nas dimensões de raça/etnia e de sexo, que constituem a classe em suas particularidades. Esta última - o sexo especificamente foi a categoria da discussão proposta. 


\section{Relações sociais de sexo na ordem capitalista}

As relações sociais de sexo são constitutivas da história das relações nas diferentes sociedades de classes, servindo como uma de suas formas de sustentação. No capitalismo, tendo em vista sua constituição intrinsecamente desigual, elas contribuem para a manutenção e o encobrimento do antagonismo e das desigualdades de classe. Tais relações são expressas pela vigência da dominação-exploração masculina em todas as esferas da vida. Essa configuração é terminantemente nomeada pela vigência da ordem patriarcal, entendida como um sistema de dominação-exploração dos homens sobre as mulheres, presente em todos os espaços de produção e reprodução da vida e que, simbiotizada ao capitalismo, constitui um dos eixos de (re)produção da atual ordem.

$\mathrm{Na}$ mesma linha de pensamento e recorrendo às discussões das feministas comunitárias (CABNAL, 2010), o patriarcado é um sistema de todas as opressões, de todas as violências, discriminações e desigualdades, historicamente construídas, sobre o corpo das mulheres. Destacamos que a superação de tais contradições e a destruição da base material do patriarcado não são possíveis nessa sociedade, pois, como ele é constitutivo/constituído dela/nela, só poderá ser superado com a superação do atual modo de produção.

Dessa forma, toda a nossa história, a nossa linguagem, a nossa racionalidade são patriarcais. O questionamento interno desse modelo torna-se necessário na medida em que estamos - todas e todos - envolvidos(as) por ele, mesmo aqueles(as) que não legitimam sua (re)produção.

A complexificação das forças produtivas - e tudo o que isso implica -, em especial sua tendência de estender seus tentáculos em todas as esferas da vida, apropriando-se e marcando modos e formas de viver e de pensar, baliza também aquilo que faz parte das relações e que constitui de maneira diferenciada a forma de ser sujeito, manifesto no sexo, na raça, na etnia, que, como indicamos, é da natureza do ser, natureza biológica e que está posta na vida porque é social, porque é relação, acentuando-se cada vez mais todo tipo de subordinação, entre elas, a das mulheres.

É nesse sentido que concordamos com Saffioti (2009, p. 30) quando expressa que, "[...] quanto mais sofisticado o método de exploração praticado pelo capital, mais 
profundamente se vale da dominação de gênero de que as mulheres já eram, e continuam sendo, vítimas". Portanto, não há, de um lado, dominação patriarcal e dominação racista e, de outro, exploração capitalista. Os três são constitutivos do sistema de dominaçãoexploração patriarcado-racismo-capitalismos que sustentam a Ordem do Capital.

Assim, capitalismo e patriarcado conformam uma dupla - e agregado a eles, o racismo -, que deve ser posta em questão como um conjunto, não podendo ser pensados separadamente, na medida em que é necessário desvelar suas relações e sua capacidade de reprodução. Conforme lasi (2014, p. 134), o caráter de nossa atual sociedade concebe “[...] uma interação dialética onde a exploração de classe [...] se dá por mediações onde uma delas, uma das fundamentais, é a opressão sobre a mulher, a hierarquização de poder e funções segundo o sexo".

Dessa forma, entendemos que a emancipação humana é atravessada pela necessidade de superação do capitalismo e, portanto, do patriarcado, que constitui e expressa a manutenção e a reprodução da exploração-dominação masculina. Entendemos que o sexo e a raça/etnia, características naturais, apresentam- se "[...] como marcas sociais que permitem hierarquizar, segundo uma escala de valores, os membros de uma sociedade historicamente dada" (SAFFIOTI, 2013, p. 60). Porém, tais caracteres não contêm em si a explicação para a conformação da realidade social e de suas determinações. Eles [...] operam segundo as necessidade e conveniências do sistema produtivo de bens e serviços, assumindo diferentes feições de acordo com a fase de desenvolvimento do tipo estrutural da sociedade (SAFFIOTI, 2013).

Concordamos, portanto, com Gonçalves (2013, p. 18), o qual assevera que

[...] o sexo, categoria de ordem natural, encobre o antagonismo de classes. 0 domínio masculino sobre as mulheres, não diretamente atrelado à estrutura econômica da sociedade, serve aos interesses daqueles que detêm o poder econômico.

A manutenção e a vigência da exploração-dominação masculina servem, portanto, como facilitadoras da realização dos interesses daqueles que ocupam posição superior na estrutura de classes, da (re)produção das desigualdades de classe, tendo em vista que "[...] certos padrões culturais forjados em outras estruturas persistem na nova [no capitalismo]" (SAFFIOTI, 2013, p. 130). 
Assim sendo, as classes sociais são atravessadas pelas desigualdades ${ }^{4}$ de sexo e de raça/etnia, logo, a força de trabalho é diferenciada em termos de sexo e raça/etnia.

\begin{abstract}
Sendo homens e mulheres seres complementares na produção e reprodução da vida, fatos básicos da convivência social, nenhum fenômeno há que afete a um deixando de atingir outro sexo. A não percepção deste fato tem conduzido a concepções fechadas de masculinidade e feminilidade. Na vida real, entretanto, as ações de homens e mulheres continuam a complementar-se, de modo que à mistificação dos seres femininos corresponde a mistificação dos seres masculinos. Assim, não são apenas as mulheres que sofrem a atuação da mística feminina; desta constituem presas fáceis também os homens (SAFFIOTI, 2013, p. 34).
\end{abstract}

De tal modo, o processo de subordinação feminina e dominação masculina constituem uma relação umbilicalmente atrelada, uma unidade contraditória, estabelecendo relações sociais de sexo desiguais e que servem ao processo de produção e reprodução da vida social posto pela ordem do capital. Particularmente, no que se refere à compreensão e à historicização do masculino, do "ser homem", é de vital importância não a desvincular do contexto patriarcal, tendo em vista que ele atravessa nossa forma de sociabilidade e, conforme apontado, serve para encobrir e, ao mesmo tempo, facilitar o processo de construção e de manutenção dos antagonismos de classe.

\title{
O trabalho: transformação do ser social
}

A realidade em que mulheres e homens estão inseridos tem sua base de construção na dinâmica imposta pelo capitalismo. Dessa maneira, entendemos que a compreensão das relações capitalistas de produção e reprodução é base fundante de qualquer análise que se direcione à apreensão das relações desiguais e hierárquicas que se estabelecem entre os seres sociais, homens e mulheres.

O modo capitalista de produção eleva ao máximo todas as contradições inerentes às formações sociais que se assentam na apropriação privada dos meios de produção e dos produtos do trabalho. A produção e a reprodução da ordem capitalista realizam-se na manutenção da apropriação da vida pelo trabalho, espraiando sua dominação ideológica,

\footnotetext{
${ }^{4}$ Colocamos desigualdades, e não antagonismo, pois homens e mulheres constituem uma classe independentemente de seu sexo-, e, nesse sentido, o antagonismo só pode existir entre as classes sociais, e não entre os sujeitos singulares que as constituem.
} 
política e econômica em todos os espaços da vida. Assim, a compreensão das relações sociais desiguais entre os sexos e a manutenção da exploração-dominação masculina, expressas pela ordem patriarcal, requerem o entendimento dessa dinâmica capitalista em sua constituição.

Importa ressaltar que o capital se sobrepuja à individualidade dos sujeitos, assim, as relações que se estabelecem na sociedade de classes entre os homens e as mulheres são atravessadas por relações de dominação-exploração, nas quais os homens se sustentam hegemonicamente em escala desigual e superior. Essas relações são, obviamente, mediadas pelas relações sociais de produção que vão se configurando no movimento do real e que se estabelecem nos diferentes momentos históricos.

Lukács (2012), ao analisar as categorias ontológicas fundamentais de Marx, compreende o trabalho como fundante do ser social. Nesse sentido,

[...] o trabalho é antes de tudo, em termos genéticos, o ponto de partida para tornar-se homem do homem, para a formação de suas faculdades, sendo que jamais se deve esquecer o domínio sobre si mesmo. Além do mais, o trabalho se apresenta, por um longo tempo, como o único âmbito desse desenvolvimento; todas as demais formas de atividade do homem, ligadas aos diversos valores, só se podem apresentar como autônomas depois que o trabalho atinge um nível relativamente elevado (LUKÁCS, 2012, p. 348).

O trabalho como fundante, como forma originária, apresenta, pois, a gênese de determinadas tendências mais gerais das diferentes formas da prática do ser social, como, por exemplo, a configuração das relações sociais. De tal modo, a especificidade fundante do ser social e de todas as suas determinações se dá pelo trabalho. Assim, o trabalho é considerado:

[...] a satisfação material das necessidades dos homens e mulheres que constituem a sociedade - obtêm-se numa interação com a natureza: a sociedade. Através dos seus membros [...] transforma matérias naturais em produtos que atendem às suas necessidades (NETTO; BRAZ, 2007, p. 30).

A reprodução do ser social, segundo Lukács (2013), acontece tendo em conta, de um lado, que o homem tem como fato ontológico ineliminável sua constituição física, biológica, e, de outro lado, que a reprodução ocorre num espaço cuja base é a natureza, mas uma natureza cada vez mais modificada pelo trabalho. Da mesma forma, na sociedade, na qual 
se verifica realmente o processo reprodutivo do homem, encontram-se cada vez menos já prontas na natureza as condições da própria reprodução, as quais, ao contrário, essa cria mediante a práxis social dos homens.

Dessa forma, o trabalho - e seus desdobramentos ontológicos - é pressuposto, direta e indiretamente, em todas as manifestações sociais, como bem explicita Marx (2013, p. 255):

\begin{abstract}
O trabalho é, antes de tudo, um processo entre o homem e a natureza, processo este em que o homem, por sua própria ação, medeia, regula e controla seu metabolismo com a natureza. [...] Agindo sobre a natureza externa e modificando-a por meio desse movimento, ele modifica, ao mesmo tempo, sua própria natureza. [...] Pressupomos o trabalho numa forma em que ele diz respeito unicamente ao homem. Uma aranha executa operações semelhantes às do tecelão, e uma abelha envergonha muitos arquitetos com a estrutura de sua colmeia. Porém, o que desde o inicio distingue o pior arquiteto da melhor abelha é o fato de que o primeiro tem a colmeia em sua mente antes de construí-la com a cera. No final do processo de trabalho, chega-se a um resultado que já estava presente na representação do trabalhador no inicio do processo, portanto, um resultado que já existia idealmente. Isso não significa que ele se limite a uma alteração da forma do elemento natural; ele realiza neste último, ao mesmo tempo, seu objetivo [...]
\end{abstract}

A partir da citação de Marx, vemos que, além de ser a atividade fundante do ser social, o trabalho, na medida em que possibilita a transformação da natureza pela humanidade, também oportuniza, por consequência, a transformação do ser social. 0 trabalho, teleologicamente posto, contém desde o início a possibilidade de produzir mais do que o necessário para a mera reprodução do trabalhador, e isso provoca alterações internas e externas na organização da sociedade.

De acordo com Lukács (2013, p. 160),

[...] o fato de que do trabalho necessariamente decorrem a fabricação de ferramentas e a utilização de forças da natureza (fazer fogo, domesticar animais etc.) faz aparecer, em certos estágios evolutivos, aqueles pontos nodais, que provocam uma mudança qualitativa na estrutura e na dinâmica de sociedades singulares, [como a criação das bases objetivas para a escravidão e o desenvolvimento do capitalismo, que tem como base de seu sistema o valor de uso da força de trabalho].

A divisão do trabalho, orginalmente, baseava-se num princípio de diferenciação biológica. Entretanto, o desenvolvimento das forças produtivas e o consequente aumento 
da riqueza alteram essa divisão primária, surgindo uma segunda ordem. Recorrendo a Engels (2009), citado por Lukács, podemos observar que

\begin{abstract}
Isso fica evidente, por exemplo, no papel que desempenham os sexos na divisão social do trabalho. Engels demonstra que a posição da mulher na vida social depende de que a multiplicação da riqueza empreste às funções econômicas do homem um peso maior que às da mulher; num estágio mais primitivo, era o inverso. Evidencia-se, portanto, [...] que a estrutura social surgida em cada estágio de desenvolvimento da reprodução determina, em última instância, as formas de uma relação biológica tão elementar quanto a sexual. Esse estado de coisas é evidente em todos os domínios (LUKÁCS, 2013, p. 162).
\end{abstract}

Desse modo, a divisão sexual do trabalho não está fora da divisão social do trabalho, ao contrário, ela é inerente à forma de organização do trabalho, subsumida ao capital. Logo, as formas ideológicas, políticas e culturais estão direcionadas para que essa "divisão sexual" funcione como mais uma maneira, uma dimensão ao movimento estabelecido. Se for homem ou mulher importará aos benefícios da valorização do valor, encoberta sobre diferentes formas, que inclusive poderão aparecer muitas vezes até "progressistas" em relação à mulher, mas, no fundo, sempre serão em favor da perspectiva de produção de maior lucro.

Isso não elimina a condição de ser mulher e de ser homem sob a ordem patriarcal, e mesmo de combater essa posição, já que se tem como pressuposto que a luta é pela emancipação do sujeito, seja ele mulher ou homem, seja sua posição feminina ou masculina, sendo que tal emancipação é o que the permite ser um ser social potencialmente livre. Por isso, hábitos e costumes que representam a lógica adequada a cada sexo na sociedade de classes precisam ser naturalizados, tendo em vista que estes (re)produzem a lógica de acumulação capitalista que limita enormemente as potencialidades dos sujeitos.

\title{
Patriarcado, relações sociais de sexo e ordem do capital
}

Nas sociedades de classes, especificamente no capitalismo, dado sua alta necessidade de limitação das potencialidades humanas, fatores de ordem natural, como os apontados no item anterior, a saber, o sexo e a raça/etnia, são tomados, aparentemente, como determinantes da hierarquização social e mesmo limitantes do processo de expansão do capital. 
Do ponto de vista da aparência, portanto, não é a estrutura de classes que limita a atualização das potencialidades humanas, mas, ao contrário, é a ausência de potencialidades de determinadas categorias sociais que dificulta e mesmo impede a realização plena da ordem social competitiva. Na verdade, quer quando os mencionados fatores naturais justificam uma discriminação social de jure, não cabe pensá-los como mecanismos autônomos operando contra a ordem social capitalista. Ao contrário, uma visão globalizadora da sociedade de classes não poderá deixar de percebê-las como mecanismos coadjutores da realização histórica do sistema capitalista de produção. Do mesmo modo como é necessário desvendar, sob a aparência do trabalho inteiramente não remunerado e de trabalho inteiramente remunerado, um quantum de trabalho necessário e um quantum de trabalho excedente, há que se desnudarem: os status adquiridos que, nas sociedades pré-capitalistas, se ocultam sob a aparência de status atribuídos; os status atribuídos que, nas sociedades de classes, assumem a forma aparente de status adquiridos através do processo da competição (SAFFIOTI, 2013, p. 59).

Essa desigualdade em relação aos caracteres naturais, notadamente os de sexo, é sustentada e estabelecida pelo patriarcado, que se apresenta como uma das dimensões que conformam as relações entre os sujeitos. O patriarcado - entendido como uma categoria histórica - anterior ao capitalismo ${ }^{5}$ é reconfigurado às funcionalidades do atual modo de produção, tendo em vista que, como uma organização que situa os sujeitos desigualmente, principalmente a partir de caracteres naturais, como o sexo, serve para encobrir os antagonismos de classe, na medida em que "justifica" esses antagonismos por uma pretensa naturalidade (assim como o racismo) e contribui para deslocar o enfrentamento da questão cerne estruturante da sociedade capitalista.

Nesse sentido, a relação entre os sujeitos passa a ser central na constituição do ser social. Assim, as relações que se estabelecem entre homens e mulheres partem de um dado biológico, o sexo, e são cada vez mais sociais à medida que são transformadas pela cultura. Ou seja, as relações puramente biológicas entre os sexos têm, necessariamente, uma condicionalidade social no que se refere às suas formas e aos seus conteúdos.

Essa relação, na sociabilidade burguesa, assim como a constituição das demais relações sociais, é necessariamente desigual, e, atravessada pelo vetor patriarcal,

\footnotetext{
${ }^{5}$ Para Silvia Federici (2015): "Las investigaciones históricas han demostrado que con el desarrollo del capitalismo, es decir con el paso del feudalismo al capitalismo, hubo un pasaje violento, porque el desarrollo del capitalismo fue como la contrarrevolución en un momento de crisis del feudalismo. El capitalismo dio una nueva fundación a las relaciones patriarcales; el capitalismo se ha apropiado de los elementos de la relación patriarcal del feudalismo, pero lo ha transformado y ha dado nuevas funciones para sus fines sociales y económicas".
} 
estabelece um processo de exploração-dominação dos homens sobre as mulheres. A sociabilidade burguesa jamais conseguirá superar a opressão da mulher. Vejamos essa questão nas palavras de Lukács (2013, p. 175): “A intimidade erótica de cunho burguês jamais conseguiu superar realmente a opressão da mulher; disso surgiu uma vasta escala que vai da falsa consciência de sincera extrapolação até a hipocrisia".

Nos marcos de nossa atual sociabilidade podemos verificar um alto grau de desenvolvimento das capacidades humanas sem que isso incorra, necessarimante, na emancipação e no desenvolvimento das personalidades dos diferentes sujeitos. Já que, como bem expressa Lukács (2013, p. 562), "o desenvolvimento das forças produtivas provoca diretamente o crescimento das capacidades humanas, mas ao mesmo tempo pode em tal processo sacrificar os indivíduos (assim como classes inteiras)".

Isso significa que o alto desenvolvimento da genarilidade - potencialidade - humana não implica necessariamente que os diferentes sujeitos que dela fazem parte caminhem nessa mesma direção e, considerando nosso modo de produção, que necessita para sua própria existencia e manutenção relações sociais aviltantes, implica que os sujeitos produzam relações cada vez mais contraditórias e estranhadas.

Nas palavras de Lukács (2013, p. 593), trata-se "do conflito socialmente originado entre desenvolvimento e desdobramento das capacidades dos homens e a formação de sua personalidade enquanto homem". Esse processo, em decorrência, apresenta suas características também nas relações que os sujeitos estabelecem entre si ${ }^{6}$.

\footnotetext{
Assim como o tornar-se homem acontece objetivamente no trabalho e no desenvolvimento das capacidades produzido subjetivamente por ele somente quando o homem não reage mais de modo animalesco ao mundo que o cerca, isto é, quando deixa de simplesmente se adaptar ao respectivo mundo exterior dado e, por seu turno, passa a participar de modo ativo e prático de sua remodelação em um meio ambiente humano cada vez mais social, criado por ele mesmo, assim também enquanto pessoa ele só pode se tornar homem se a sua relação com o seu semelhante humano assumir formas cada vez mais humanas, como relações entre homens e homens, e dessa forma se realizarem na prática (LUKÁCS, 2013, p. 596).
}

\footnotetext{
${ }^{6}$ Sínteses de notas de Conferência ministrada pelo Prof. Dr. Ronaldo Vieira Fortes no III Encontro de Teoria Social, Educação e Ontologia Crítica, realizado de 7 a 9 de outubro de 2014.
} 
Destarte, as relações entre os sujeitos estão, igualmente, entranhadas no processo das relações sociais. Como nos lembra Marx, a forma mais imediatada em que tais relações podem ser verificadas é na relação imediata homem-mulher, que segundo o autor expressa de modo bastante incisivo o desenvolvimento do gênero humano.

\begin{abstract}
A relação imediata, natural, necessária do homem com o homem é a relação do homem com a mulher. Nesta relação genérica natural a relação do homem com a natureza é imediatamente a sua relação com o homem, assim como a relação com o homem é imediatamente a sua relação com a natureza, a sua própria determinação natural. Nesta relação fica sensivelmente claro portanto, e reduzido a um factum intuível, até que ponto a essência humana veio a ser para o homem natureza ou a natureza [veio a ser] essência humana do homem. A partir desta relação pode-se julgar, portanto, o completo nível de formação (die ganze Bildungsstufe) do homem. Do caráter desta relação segue-se até que ponto o ser humano veio a ser e se apreendeu como ser genérico, como ser humano; a relação do homem com a mulher é a relação mais natural do ser humano com o ser humano (MARX, 2009, p. 104-105).
\end{abstract}

O lugar dos homens como dominadores-exploradores expressa, apenas, a condição da humanidade no atual estágio de desenvolvimento. É uma expressão concreta, palpável da expropriação e da natureza limitadora das relações sociais pautadas na apropriação da vida pelo trabalho e, mais especificamente, expressão concreta das relações sociais produzidas sob o modo de produção capitalista.

Na medida em que o capitalismo estende seus domínios, ele expropria os(as) trabalhadores(as) de seus meios de vida e de sua força trabalho, tornando o trabalho cada vez mais coletivo, e a apropriação de seu produto cada vez mais privada. Quer dizer, aquilo que é produzido pelo trabalhador na esfera privada torna-se social na medida em que é demandado por necessidades coletivas capitalistas de valorização do valor. Esse processo constitui as relações entre os indivíduos sociais que, por seu turno, são mediatizadas pela mercadoria que produzem, as quais adquirem um valor monetário que deve gerar lucro aos possuidores dos meios de produção.

Os produtos do trabalho têm, portanto, um valor de uso, que é expresso pela sua capacidade de satisfazer diretamente a necessidade de seus produtores e, no capitalismo, devem ter um valor de troca ${ }^{7}$, que se expressa por meio do tempo de trabalho socialmente

\footnotetext{
7 “A mercadoria é valor de uso - ou objeto de uso - e 'valor'. Ela se apresenta em seu ser duplo na medida em que seu valor possui uma forma de manifestação própria, distinta de sua forma natural, a saber, a forma do valor de troca, e ela jamais possui essa forma quando considerada de modo isolado, mas sempre apenas
} 
necessário para a sua produção, é a dimensão quantitativa dos produtos do trabalho. $\mathrm{O}$ tempo de trabalho socialmente necessário é determinado pelo tempo médio que um trabalhador, em determinado período histórico, leva para a produção de determinada mercadoria.

Nos marcos do atual modo de produção, há uma forte cisão entre valor de uso e valor de troca, em que este último atravessa todos os artigos produzidos e os define como mercadoria, determinando inclusive a própria força de trabalho ${ }^{8}$, tendo em vista que o trabalhador e a trabalhadora não produzem mais diretamente para seu consumo, ou seja, produzem mercadorias que não expressam diretamente suas necessidades enquanto produtores singulares, ao mesmo tempo em que reproduzem sua força de trabalho como mercadoria.

Nesse sentido, e como já explicitamos, a reprodução do modo de produção capitalista, é atravessada, desde a sua gênese, por relações sociais de produção desiguais e hierárquicas. Tal reprodução, inerente a tal modo de produção, requer a construção e a manutenção de relações sociais desiguais.

Nesse contexto, a posição hierárquica e inferior das mulheres em relação aos homens, que vem sendo construída há milênios, desde antes do modo de produção atual, garante que essa configuração seja potencializada, pois destina espaços sociais diferenciados para ambas as categorias de sexo, homens e mulheres. Estas últimas em posição subalternizada, que também serve para elevação do montante de trabalho excedente. Dessa forma, faz-se necessário também analisar o lugar que as relações sociais de sexo situam os diferentes sujeitos, particularmente os homens, tendo em vista que,

na relação de valor ou de troca com uma segunda mercadoria de outro tipo. Uma vez que se sabe disso, no entanto, aquele modo de expressão não causa dano, mas serve como abreviação" (MARX, 2013, p. 136).

8 "O valor da força de trabalho, como o de todas as outras mercadorias, é determinado pelo tempo de trabalho necessário para a produção - e, consequentemente, também para a reprodução - desse artigo específico. Como valor, a força de trabalho representa apenas uma quantidade determinada do trabalho social médio nela objetivado. A força de trabalho existe apenas como disposição do indivíduo vivo. A sua produção pressupõe, portanto, a existência dele. Dada a existência do indivíduo, a produção da força de trabalho consiste em sua própria reprodução ou manutenção. Para sua manutenção, o indivíduo vivo necessita de certa quantidade de meios de subsistência. Assim, o tempo de trabalho necessário à produção da força de trabalho corresponde ao tempo de trabalho necessário à produção desses meios de subsistência, ou, dito de outro modo, o valor da força de trabalho é valor dos meios de subsistência necessários à manutenção de seu possuidor" (MARX, 2013, p. 245). 
Por se ter deixado iludir com a identificação da masculinidade com a capacidade de mando, o homem consente na competição desigual de que são atores representantes das duas categorias de sexo, com desvantagens para as mulheres, contribuindo assim, enormemente, para a preservação de um status quo reificante. Neste contexto, ganha nova dimensão a asserção de Simone de Beauvoir de que "o problema da mulher sempre foi um problema dos homens". Como um dos agentes do processo de mistificação da mulher, o homem, tanto burguês quanto proletário e, sobretudo pertencente aos estratos sociais médios, presta colossal auxílio à classe dominante e mistifica-se a si próprio (SAFFIOTI, 1979, p. 41).

Entende-se, portanto, que a compreensão da categoria patriarcado de uma forma ampla torna-se necessária, uma vez que ela exprime a manutenção de processos desiguais e hierarquizantes estabelecidos na e pela ordem capitalista. O que significa que o patriarcado se conforma enquanto um sistema de dominação-exploração funcional à ordem do Capital e que contribui para sua sustentação, na medida em que, ao tomar os caracteres naturais desigualmente, situa e potencializa também nesses termos as desigualdades de classes.

\section{Considerações finais}

O questionamento propulsor da pesquisa realizada, que, no presente texto, apresentamos uma parte do processo, centrou-se na necessidade de compreensão sobre como, no processo de complexificação das relações sociais, as características biológicas inerentes ao ser social vão sendo tomadas como marcas de desigualdades e tornam-se um elemento de exploração-dominação na ordem do capital. Nesse caso específico, como as relações sociais de sexo apresentam-se nesse contexto.

Entendemos que a dominação-exploração masculina e a subordinação das mulheres constituem um processo histórico, que intensifica a exploração do capital sobre o trabalho. O capital impõe a desigualdade em todas as esferas sociais, no microcosmo e no macrocosmo social. Logo, a constituição das relações sociais de sexo desiguais é intrínseca às relações sociais capitalistas, dado que estas são basilares da produção e da reprodução da vida material. Conforme procuramos indicar, caracteres naturais, como o sexo e a raça/etnia, são assimilados como marcas de desigualdades nessa organização social.

As relações sociais construídas sob a égide do modo de produção capitalista são, então, atravessadas por desigualdades e hierarquias. O são pois a produção e a reprodução da vida são assim pautadas: desiguais e hierárquicas. Ou seja, existem sujeitos que acessam 
mais privilégios que outros dependendo da posição em que estão nessa relação social. Posição esta determinada pela relação de classe e pelas contradições inerentes a ela, assim como também os desdobramentos ou as dimensões dessa contradição, como o sexo e a raça/etnia. Nos limites do presente texto, procuramos dar ênfase a duas delas: o sexo e a classe.

Concordamos com Souza-Lobo (1991): a classe trabalhadora não é homogênea, ela tem sexo e é, consequentemente, ainda mais aviltada pelas contraditórias relações constituídas. Tais relações, que tem sua base material dada pela organização social capitalista, atribuem posições desiguais e hierarquizadas para mulheres e homens. Privilegia estes em detrimento das primeiras.

Quando falamos de classe e de sexo, a intencionalidade é pontuar que estamos falando de sujeitos que tem relações sociais que são distintas. A relação que a classe trabalhadora tem com a exploração-dominação é o momento predominante. Portanto a faz-se necessária a discussão da desigualdade entre os sexos, da dominação-exploração masculina, ou seja, é necessário o debate com o recorte de classes. É a classe trabalhadora que vivencia mais concretamente a força da exploração da ordem do capital e de suas dimensões de sexo e raça/etnia - e demais relações subalternizantes que surgem dessa ordem.

Logo, as relações sociais entre os sujeitos são sexuadas, são produzidas por homens e mulheres, e, tendo sua base material dada pelo trabalho, expressas pela divisão sexual do trabalho. A lógica de exploração do trabalho imposta na ordem capitalista cria, em seus meandros e objetivando o aumento dessa exploração, a desigualdade entre os sujeitos, que inclui a construção e a manutenção das desigualdades entre os sexos.

Esse processo de organização, entretanto, e conforme procuramos indicar neste texto, não tem sua gênese somente nesse modo de produção, já que as relações desiguais entre os sexos são produtos históricos de formações anteriores ao modo de produção capitalista. Por isso a importância de nomear especificamente essa dimensão dentro da ordem do capital, tendo em vista que, mesmo sendo uma de suas forças estruturantes, pode atravessá-la em temporalidade.

Destarte, entendemos que a categoria patriarcado dá nome a essas relações sociais desiguais entre os sexos e se mantém como uma dimensão estruturadora de sua 
reprodução, explicitando a vigência da exploração-dominação masculina. A manutenção da ordem patriarcal e, portanto, da dominação-exploração masculina é necessária para a continuidade da (re)produção sociometabólica do capital.

Em outras palavras, a ordem patriarcal se mantém funcional à dominação capitalista e, ao mesmo tempo, ao elaborar desigualmente fatores naturais, encobre os antagonismos de classes. Avanços, dentro da ordem do capital, são possíveis, como aponta Mészáros (2002), entretanto, a supressão desse ordenamento pressupõe uma organização social na qual essas desigualdades não sejam mais úteis, funcionais. Uma organização para além do capital

Para finalizar, consideramos que as relações sociais de sexo têm sua base material dada pela organização social capitalista, que atribui posições desiguais e hierarquizadas para mulheres e homens. Privilegia estes em detrimento das primeiras. São diversas as formas de materialização desses privilégios que, no limite, incidem em situações de violência. Situações de violência - seja ela verbal, seja ela "sutil", seja ela física - são a expressão mais visceral e escancarada de nossa sociabilidade que nos faz "esquecer" de nossa humanidade.

Abrir mão do que nos é apresentado como privilégio é um processo que devemos perquirir todos os dias, em todas as nossas relações. Aos homens, enquanto indivíduos e categoria social, faz-se necessária a compreensão que toda a resistência e a luta pela construção de uma nova forma de relação entre os sujeitos passa pela não menos necessária destruição das relações de submissão que são estabelecidas e direcionadas às mulheres, enquanto indivíduos e categoria social.

O mesmo processo que provoca a formação de nossa consciência de classe provoca (ou deveria provocar) nossa consciência feminista. O patriarcado e o capitalismo (e o racismo) são estruturantes das nossas relações sociais, desde as mais complexas às "micro" relações, às relações "afetivas". A desconstrução das formas de relações entre os sujeitos que aviltam constantemente suas potencialidades é essencial para a construção de uma sociedade com sujeitos não explorados. Para tanto, é necessário nomear explicitamente sua configuração e sua base de sustentação, a exploração de classe. E, nesse sentido, não perder o horizonte de transformação social almejado. 


\section{Referências}

BARROCO, M. L. S. Ética e serviço social: fundamentos ontológicos. 2. ed. São Paulo: Cortez, 2003.

CABNAL, L. Feminismos Diversos: el feminismo comunitario. Madri: ACSUR-Las Segovias, 2010.

ENGELS, F. A origem da família, da propriedade privada e do Estado. São Paulo: Escala, 2009.

FEDERICI, S. Patriarcado del salario: lo que llaman amor, nosotras lo llamamos trabajo no pagado. Prensa Comunitaria, Guatemala, 21 abr. 2015. Entrevista concedida a Gladys Tzul Tzul.

GONÇALVES, R. O pioneirismo de a mulher na sociedade de classes. In: SAFFIOTI, H. I. B. A mulher na sociedade de classes: mito e realidade. São Paulo: Expressão Popular, 2013.

HELLER, A. Para mudar a vida. São Paulo: Brasiliense, 1982.

IASI, M. As ruas: poemas e reflexões pedestres. São Paulo: Instituto Caio Prado Jr., 2014.

LUKÁCS, G. Para uma ontologia do ser social I. São Paulo: Boitempo, 2012. . Para uma ontologia do ser social II. São Paulo: Boitempo, 2013.

MARX, K. Manuscritos econômico-filosóficos. São Paulo: Boitempo, 2009. . O capital. São Paulo: Boitempo, 2013.

MÉSZÁROS, I. Para além do capital: rumo a uma teoria da transição. São Paulo: Boitempo, 2002.

NETTO, J. P. Introdução ao estudo do método em Marx. São Paulo: Expressão Popular, 2011.

; BRAZ, M. Economia política: uma introdução crítica. São Paulo: Cortez, 2007.

SAFFIOTI, H. I. B. A mulher na sociedade de classes: mito e realidade. Petrópolis: Vozes, 1979.

. O Poder do Macho. São Paulo: Moderna, 1990.

. Diferença ou indiferença: gênero, raça/etnia e classe social. In: ADORNO, S. (Org.). A sociologia entre a modernidade e a contemporaneidade. Porto Alegre: Ed. UFRGS, 1995.

Ontogênese e filogênese do gênero: ordem patriarcal de gênero e a violência masculina contra as mulheres. 2009. Disponível em: 
<http://www.flacso.org.br/portal/pdf/serie_estudos_ensaios/Heleieth_Saffioti.pdf>. Acesso em: 29 abr. 2013.

A mulher na sociedade de classes: mito e realidade. São Paulo: Expressão Popular, 2013.

SOUZA-LOBO, E. A classe operária tem dois sexos: trabalho, dominação e resistência. São Paulo: Editora Brasiliense, 1991.

TONET, I. Educação, cidadania e emancipação humana. Juí: Unijuí, 2012.

VIANA, N. S. Emancipação feminina e emancipação humana. Revista Espaço Acadêmico, Maringá, v. 9, n. 107, p. 40-47, 2010.

Recebido em: 02/10/2015

Aprovado em: 26/11/2015 